\title{
Exploring the attitude of Faculty of Medicine students about herbal products usage: A cross-sectional study
}

\author{
Emilija Kostić ${ }^{1}$, Milica Milutinović ${ }^{1}$, Milica Kostić ${ }^{1}$, Jasmina Petrović ${ }^{2}$, Bojana \\ Miladinović ${ }^{1}$, Suzana Branković ${ }^{3}$, Maja Vujović ${ }^{1}$, and Dušanka Kitićl, ${ }^{*}$ \\ ${ }^{1}$ University of Niš, Faculty of Medicine, Department of Pharmacy, Blvd. Zorana Đinđića 81, 18000 Niš, Serbia \\ ${ }^{2}$ University of Niš, Faculty of Philosophy, Department of Sociology, Ćirila i Metodija 2, 18000 Niš \\ ${ }^{3}$ University of Niš, Faculty of Medicine, Department of Physiology, Blvd. Zorana Đinđića 81, 18000 Niš, Serbia \\ *Corresponding author: dusanka.kitic@medfak.ni.ac.rs
}

Published: December 25, 2019

\begin{abstract}
Herbal products have gained popularity, and they are often perceived as safe. The roles of the pharmacists and physicians are essential in the proper usage of those products. This study aimed to investigate the students of Faculty of Medicine in Niš about the use of herbal preparations and the differences between medicine, pharmacy and dentistry students. The fifth-year university students were questioned through an anonymous survey. The obtained results were processed statistically and presented graphically. The majority of the students would prefer a combination of herb product and drug (76.9\%). Usage of herbal products is based on students' knowledge, on the advice of pharmacists, family members, physicians, and the media. The majority of students purchase herbal products in the pharmacy and nobody obtained them via the Internet. Most of the students used them in preventive purposes $(60 \%)$ and claimed that there were positive effects. Students $(75 \%)$ read the instructions for use and side effects, especially pharmacy students $(88.3 \%)$. Medicine students $(60 \%)$ consider herbal products completely safe. Pharmacy students are considered to receive the necessary knowledge on herbal products $(68.3 \%)$, while a smaller percentage of medicine and dentistry students consider the same. Students use herbal medicines but are not entirely familiar with their effects and safety. There is a need for raising awareness, the importance of side effects and interactions of herbs and drugs among medicine and dentistry students. This goal can be achieved by changing curriculum which would contain material from phytotherapy.
\end{abstract}

Key words: herbal products; survey; attitude; students; Faculty of Medicine

http://dx.doi.org/10.5937/leksir1939069K

\section{INTRODUCTION}

Until the appearance of synthetic drugs, man was treated entirely with the substances obtained from nature, primarily, from plants. Since it is clearly understood over time that synthetic drugs have had numerous side effects, humanity has been slowly turning more to natural medicinal products (Petrovska, 2012). Therefore, there is a huge increase in interests in alternative methods of treatments in the modern world (Pan et al., 2013). Various demographic studies indicate that $75-90 \%$ of the world's rural population uses medicinal herbs for healing or health protection (Chekole, 2017; Cujić et al., 2015). A general belief that herbal drugs are safe, considering that they improve health, the low cost of some herbal preparations and availability on the market have led to the extensive use of herbal medicines worldwide nowadays (Ekor, 2014).

It is fairly known that synthetic drugs have many adverse effects, but herbal preparations are considered to be mostly free of them (Walker and Donovan, 1999). Herbal remedies are complex mixtures of organic compounds, and they can cause adverse effects owing to their active ingredients or interactions with conventional drugs (Bent, 2008). In this regard, self-medication is a significant therapy problem nowadays. This form of treatment can be the cause of the lack of recognition and the masking of symptoms of the underlying disease as well as the interaction with primary therapy (Corrêa da Silva et al., 2012). Therefore, overall quality of healthcare is dependent on the level of knowledge and attitude of health care professionals, pharmacists, doctors and nurses, about different origins of the medicines which prevent misuse and 
improper use of herbal medicines (Builders, 2019; Clement et al., 2005).

In the international setting, the use of herbal preparations was investigated among various populations. Nevertheless, data on herbal preparations use and attitude among medicine, dentistry and pharmacy students in this region of the world are limited. Also, two stimulating factors for initiating this study were the popularity of herbal medicines and their increasing clinical importance.

The study is set to assess the awareness, perceptions, and use of herbal preparations among students at the Faculty of Medicine in Niš, Serbia. The incorporation of herbal remedies into health professional curricula of different study programs is handled differently. The Master of Pharmacy curriculum at this University integrates herbal medicine education throughout the third and fourth year of the pharmacy curriculum. Because medicine and dentistry students have subjects studying neither phytotherapy nor pharmacognosy during their studies, the aim was to assess the difference between medicine, dentistry and pharmacy students' usage and attitude towards herbal preparations, as well as the factors that might affect attitudes.

\section{MATERIALS AND METHODS}

\subsection{Study design}

This research was conducted on the Faculty of Medicine, University of Niš, Serbia, during January 2017 in the form of a cross-sectional study. The study included the fifth-year pharmacy, dentistry and medicine students. It was intended to assess the impact of education and sex on the use of herbal preparations. The survey was done based on the relevant literature. Its applicability and comprehensiveness were assured by field-testing. The survey consisted of 17 questions posted on social network and students were asked to answer the questions. There was no possibility to take a survey more than once. The first group of questions enquired information about their field of study and sex. The second group of questions asked about their and relatives' habits of use of herbal preparations (place of purchasing, a frequency of use, treatment or prevention use, their experiences). Next group of questions was important because of the investigation of the sources of information about herbal preparations and the influence of media on their decision to use herbal preparations. Eventually, the attitude of students toward the safety of herbal preparations, the habit of reading the instructions for use and satisfaction with knowledge of herbs were investigated.

\subsection{Statistical analysis}

The obtained data were statistically analyzed using appropriate tests for the determination of statistical significance (chi-square test of independence with correction of continuity according to Yeats) and descriptive statistics and presented through tables and figures. The database was created in Microsoft Excel, and SPSS 19.0 was applied for statistical significance calculations. It was set that the null hypothesis was equal to or less than $5 \%$ (the significance was defined as a $\mathrm{P} \leqslant 0.05)$.

\section{RESULTS AND DISCUSSION}

The survey was taken of 136 participants, including 66 $(48.55 \%)$ pharmacy students, $60(44.12 \%)$ medicine and 10 (7.35\%) dentistry students. Among 136 students participating in the study, $105(77.21 \%)$ were female, and $31(22.82 \%)$ were male students.

The preference for the use of herbal preparations concerning the sex and studying group of participants is shown in Figure

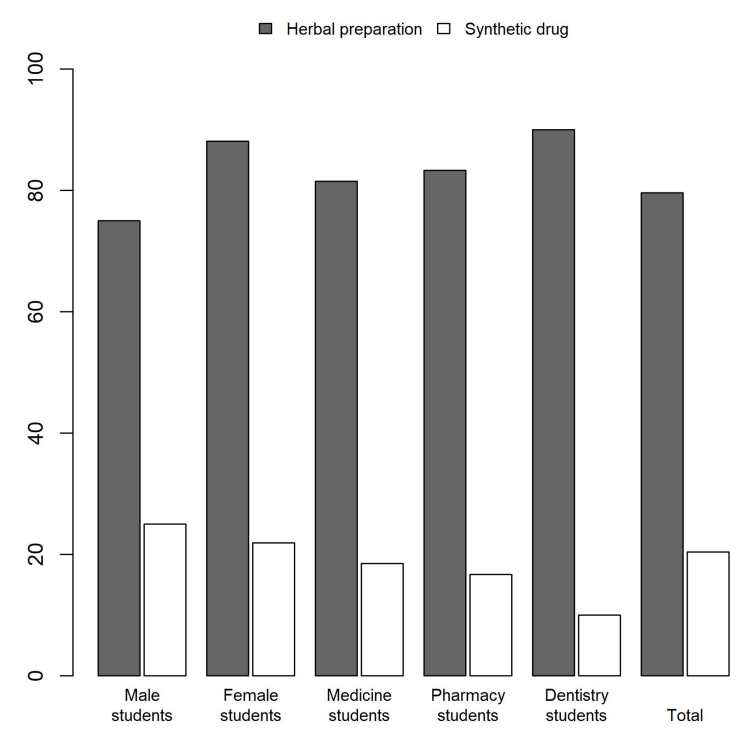

Fig. 1. The preference for the use of herbal preparations concerning the sex and studying group of participants (pharmacy, dentistry and medicine students) presented as \% of the answers on the question: "Do you prefer using herbal preparation or synthetic drug, considering severity of the symptoms?"

1. In our research, medicine students showed less trust in the efficiency of herbal preparations, compared to the group of pharmacy and dentistry students. On the first question, $84.56 \%$ of the participants answered they would choose the herbal preparation over the synthetic drug. They were informed in the questionnaire that the severity of the symptoms had to be considered. A synthetic drug would be selected by $10 \%$ of dentistry students, $11.66 \%$ of pharmacy students and $19.67 \%$ of medical students.

The frequency of the use of herbal preparations concerning the sex and studying group is shown in Figure 2. When asked how often they used herbal preparations, most students replied that they used herbal preparations sometimes $(54.4 \%)$, rarely $(25 \%)$, often $(14.7 \%)$, usually $(2.2 \%)$ and never $(3.7 \%)$. A statistically significant difference was observed among the studying groups on the frequency use of herbal preparations $\left(\chi^{2}{ }_{(8)}=18.04, \mathrm{p}=0.02\right)>\left(\chi^{2}{ }_{(8)}=15.51, \mathrm{p}=0.05\right)$. There are $18.2 \%$ of dentistry students and $61.7 \%$ of pharmacy students who use herbal preparations usually, whereas there are only $1.5 \%$ of medical students with the same habit. It can be assumed that prevalence of use of herbal preparations is mostly present in population of pharmacy students. The medicinal herbs are widely-used by students of Faculty of Medicine in Niš, which is in accordance with surveys conducted among students in India. In India, the Ayurvedic treatment system is incorporated into the health care system, so herbal preparations are in the extensive use (Sekhri et al., 2013). The results of the studies in the United States showed that $72 \%$ of the examined patients had used herbal preparations with prescribed therapy, and $84 \%$ used it in combination with OTC (over the counter preparations) (Gardiner et al., 2007a). Students' family members from different studying groups in our research $40.4 \%$ use herbal preparations usually, $51.5 \%$ use herbal preparations occasionally and only $8.1 \%$ do not use herbal preparations. The obtained results are in a good correlation with the attitude of students toward the use of herbal preparations.

Physicians and pharmacists play an important role in informing, creating users' attitudes and developing a culture on used medicinal herbs. Increased use of these products is not possi- 
- Usually $\quad$ Often $\square$ Sometimes $\square$ Rarely $\square$ Never

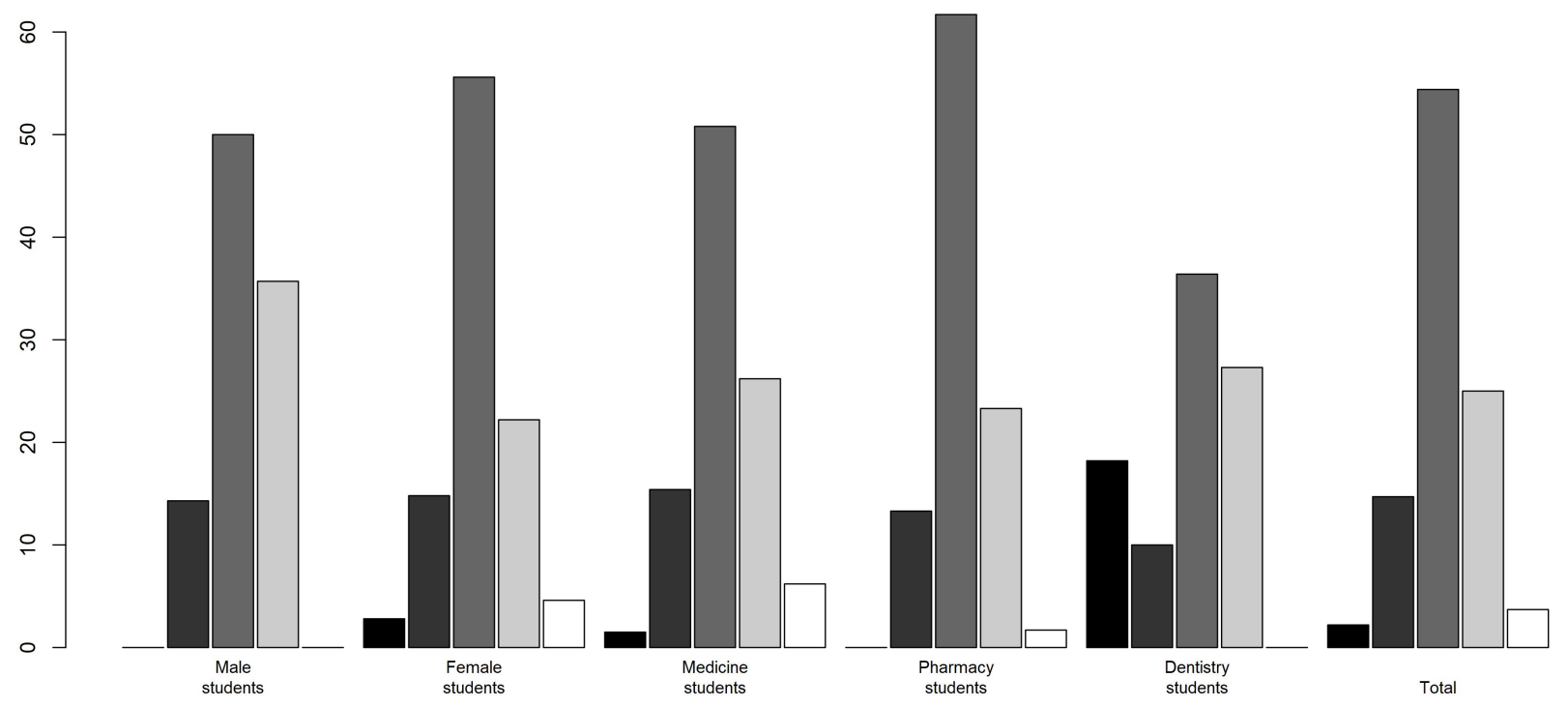

Fig. 2. The frequency of the use (\%) of herbal preparations in relation to studying groups and sex differences.

ble without changes in the attitudes and knowledge of both the pharmacists and physicians (Wahner-Roedler et al., 2006). The influence of physicians, pharmacists, family members, friends, and media information on the usage of herbal preparations based on sex and studying group was tested (Figure 3). There is a statistically significant difference among the studying groups in perception about recommendations for using herbal preparations $\left(\chi^{2}{ }_{(52)}=105.98, \mathrm{p}=0.00\right)>\left(\chi_{(52)}^{2}=67.51\right.$, $\mathrm{p}=0.05)$.

The analysis showed that $5.8 \%$ of students use herbal preparations based only on the advice of the physician, the pharmacist $5.9 \%$, family members and friends $7.3 \%$, the media $6.6 \%$, and based on their knowledge $12.4 \%$ (Figure 3). Others have suggested that the use of herbal preparations is based on recommendations from multiple sources. The results of the survey showed that $12 \%$ of participants have more trust in pharmacists' advice than in physicians' advice. Studies of Nur (2010), Howell et al. (2006) and Boparai et al. (2017) have shown that there is no proper communication between physicians and patients and that patients do not inform the physician about the use of herbal preparations. The results of the studies of Samojlik et al. (2013) and Newberry et al. (2001) have shown that $88.9 \%$ and $75 \%$ of participants, respectively, answered that they do not consider that it is important to emphasize that they use the herbal preparation with the prescribed therapy. Majority of the students (89.2\%) in a similar study were never asked about their previous use of herbal products by their physicians (Ameade et al., 2016). In two different survey-based studies conducted by Kennedy et al. (2008) and Gardiner et al. (2007b), nearly $70 \%$ of patients did not inform their physician about herbal drug consumption together with allopathic medicines. It was found that many physicians do not feel adequately prepared to advise patients on herbal preparations use (Wahner-Roedler et al., 2006).

More than $50 \%$ of the survey participants stated that pharmacists suggest using herbal preparations at the pharmacy. It is shown on Figure 4. It was interesting to note that there is a statistically significant difference in responses of students of different studying groups $\left(\chi^{2}{ }_{(4)}=12.15, \mathrm{p}=0.02\right)>\left(\chi^{2}{ }_{(4)}=9.49\right.$, $\mathrm{p}=0.05)$. Pharmacy students answered that pharmacists recommend herbal preparations $(26.7 \%)$, whereas a smaller number of dentistry and medicine students gave the same answer (18.2

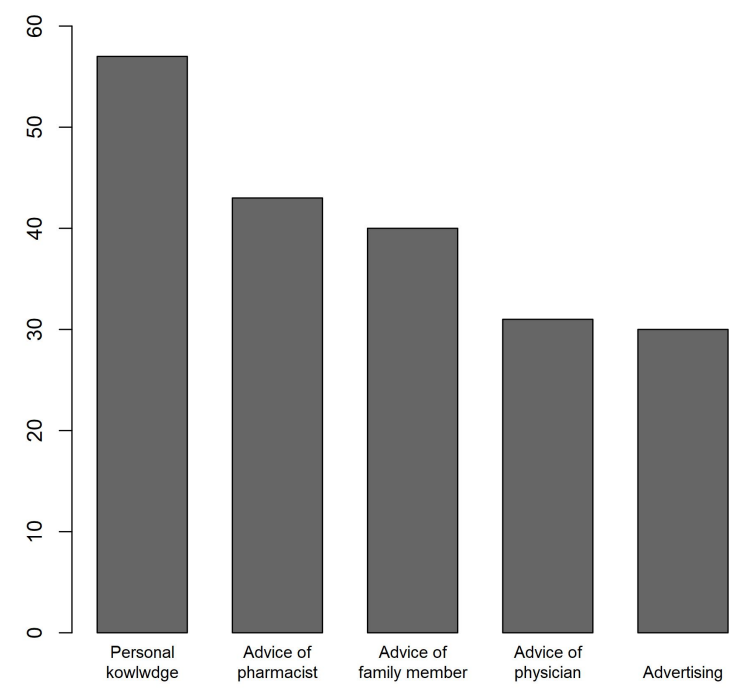

Fig. 3. Frequency of the answers on the question: "How do you decide to use herbal preparations?"

and $13.8 \%$, respectively). The reason for this difference can be the attention of pharmacy students on pharmacist advice, as well as their recognition that a preparation contains an herbal component, while medicine students and dentistry do not pay attention to the composition of the drug.

A significant determinant that affects herbal usage, whenever provided, was education. As expected, most participants who decide to use herbal preparations based on their knowledge are pharmacy students. Since medicine and dentistry students have not acquired enough knowledge on herbal preparations during their academic courses, they have been getting information about these drugs from their families and media. Our assumption that use of herbal preparations among students is positively affected by their families is proved to be valid, which was consistent with the study conducted among stu- 
dents in Slovenia by Strgar et al. (2013), in India by Sekhri et al. (2013) and in the USA by Perkin et al. (2002). This fact was also confirmed by the resemblance in responses among pharmacy, medicine and dentistry students.
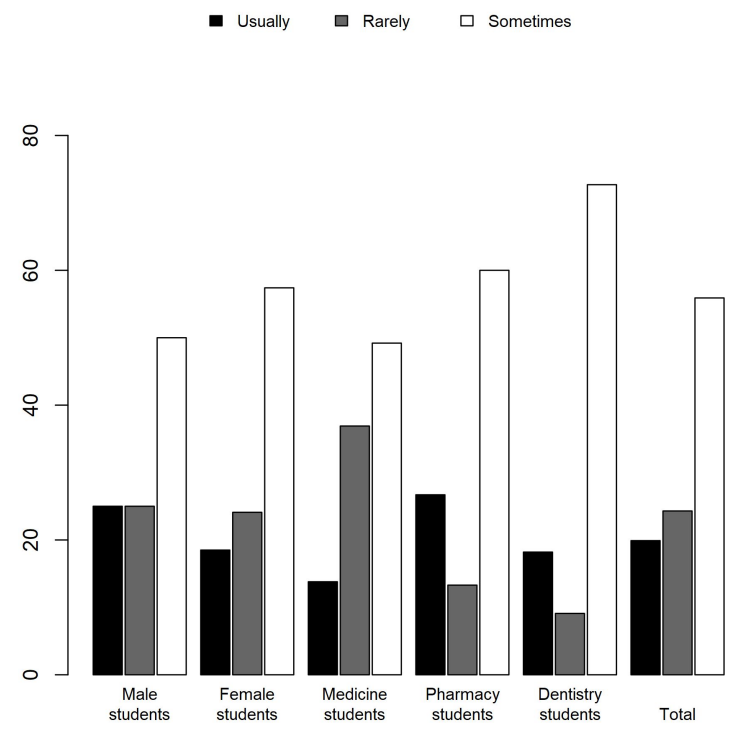

Fig. 4. Frequency of the answers on the question: "Do pharmacists recommend you herbal preparations?"

The influence of media on the use of herbal preparations is shown in Figure 5. A statistically significant difference was observed between the sexes regarding the media and advertising influence on the use of herbal preparations $\left(\chi_{(2)}^{2}=7.40\right.$, $\mathrm{p}=0.03)>\left(\chi_{(2)}^{2}=5.91, \mathrm{p}=0.05\right)$. The influence of advertising was more prevalent in the group of female students. Advertising affects the attitude of $49.3 \%$ of all participants. Only $11 \%$ of participants answered that the media did not influence their decision on the use of herbal preparations.

Pharmacy is the first choice for the majority of students to purchase the herbal preparations. No one purchases them via the Internet. A smaller number of students collect herbs in nature or buy them at the market. Other participants purchase herbal preparations from multiple sources. The results show that there is a statistically significant difference in student responses depending on the study group $\left(\chi_{(12)}^{2}=31.54, \mathrm{p}=0.02\right)$ $>\left(\chi^{2}{ }_{(12)}=21.03, p=0.05\right)$. It can be assumed that the reason for this difference is the knowledge of the importance of the safety, quality, and standardization of herbal preparations of pharmacy students (Bent, 2008). The fact that there are no positive answers that students buy herbal preparations via the Internet is a good sign of recognition by students that it is not safe. More than half of drugs and herbal preparations selling on the Internet are false (Yoshida et al., 2015).

Results of our study show that the most significant number of students uses herbal preparations for treatment of different conditions-close to $60 \%$. According to the answers on the question about purposes of herbal preparations, it can be hypothesized that preventive purposes are neglected in surveyed population. Different herbal preparations have potential in the prevention of many diseases, so these preparations should be used wider (Sofowora et al., 2013).

Most participants, as one of several indications offered in the question, referred to a cold $(79.6 \%)$, a dysfunction of immunity system $(57.7 \%)$, a urinary infection $(40.9 \%)$ and digestion problems (37.2\%). Herbal products are the first choice for $19.7 \%$ of the students for the treatment of skin changes. For weight reduction, herbal preparations are used by $8 \%$ of students, for insomnia $11 \%$, anxiety $8.8 \%$ and depression $2.2 \%$.

Students in a similar study carried out in the USA indicated that the most frequent conditions treated with herbal preparations are musculoskeletal conditions, stomach or intestinal illnesses, anxiety/depression, insomnia, cholesterol, severe headache or a migraine, menopause, and recurring pain (Gardiner et al., 2007b). It shows that tradition and variety of herbs which grow in different countries have a significant influence on the attitude toward herbal preparations usage.

The effectiveness of herbal therapy is an important issue. There are $21.3 \%$ of participants who claimed that their conditions were cured after using herbal preparations. There was no improvement in only $3.7 \%$. Most participants experienced partial improvement. In $100 \%$ of pharmacy students, there was improvement or healing their conditions. This goal can be associated with their knowledge about the proper selection and preparation of herb (infuse, macerate, tincture, etc.), which eventually affect the effectiveness of the therapy. Likewise, $86.6 \%$ of respondents in the survey conducted in Trinidad believed that herbal remedies were equally or more efficacious than conventional medicines for specific ailments and diseases (Clement et al., 2007).

A statistically significant difference was among the studying groups about the preferred pharmaceutical form of herbal preparations $\left(\chi_{(4)}^{2}=11.61, \mathrm{p}=0.02\right)>\left(\chi_{(4)}^{2}=9.49, \mathrm{p}=0.05\right)$. The most common form of herbal preparations applied by students of all studying groups is tea $(82.4 \%)$. Although they prefer tea, pharmacy students often use capsules and tablets. Students of medicine and dentistry use all three forms of herbal remedies, and solid preparations are at the bottom of the list.

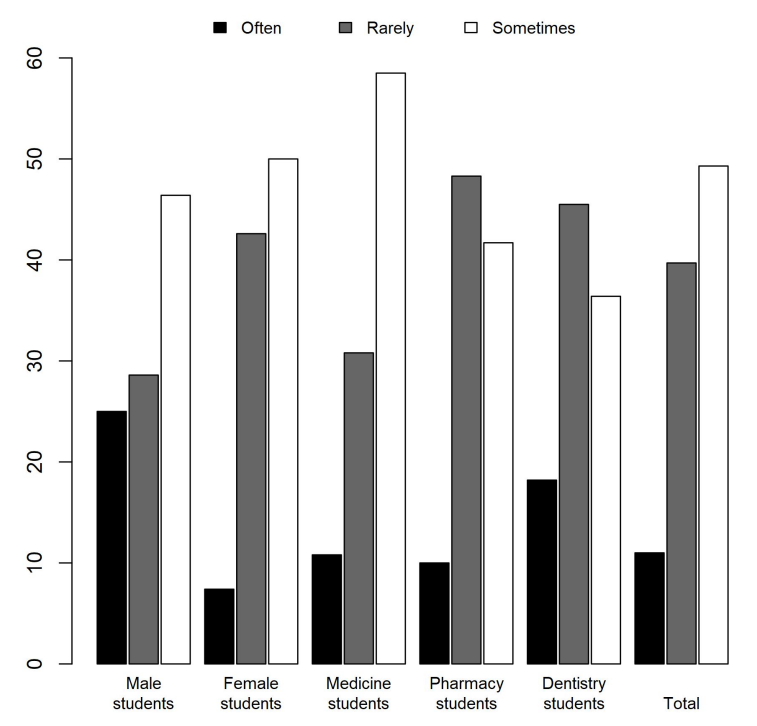

Fig. 5. The influence of the advertising on usage of herbal preparations in relation to studying groups and sex differences

When it comes to reading instructions for use and adverse effects and contraindications, students' interests seem to have the most considerable influence. A statistically significant difference among study groups exists $\left(\chi^{2}{ }_{(4)}=13.38, \mathrm{p}=0.001\right)$ $>\left(\chi^{2}{ }_{(4)}=9.49, \mathrm{p}=0.05\right)$. Most students $(75 \%)$ get acquainted with the instructions for use and adverse effects, of which are pharmacy students the majority - 88.3\% (Figure 6). Pharmacy students more often read the instructions for use and adverse effects, interactions, because of their higher interest and knowledge of the possibility of adverse effects and contraindications 
of herbal preparations, while students of medicine and dentistry do not expect them. The results were expected, considering pharmacy students' knowledge. A high percentage of medical students and dentistry who believe that herbal preparations are safe indicates that there is insufficient awareness among these students that these preparations can cause many side effects, can be toxic, or interact with many drugs.

It could be said that a statistically significant difference among the studying groups in the students' consideration about the safety of herbal preparations was expected $\left(\chi^{2}{ }_{(2)}=12.65\right.$, $\mathrm{p}=0.002)>\left(\chi^{2}{ }_{(2)}=5.99, \mathrm{p}=0.05\right)$, but the difference between sexes was not $\left(\chi_{(1)}^{2}=7.54, \mathrm{p}=0.006\right)>\left(\chi_{(1)}^{2}=3.84, \mathrm{p}=0.05\right)$. Most medical students $(60 \%)$ consider the use of herbal preparations completely safe, while participants with the same attitude are $45.5 \%$ of dentistry students and $28.3 \%$ of pharmacy students. Awareness about the safety of use of herbal preparations was most marked in the group of pharmacy students. The majority of medicine and dentistry students in this study, believing herbal preparations completely safe, revealed unawareness of possible harmfulness of herbal preparations. Despite the proven benefits of using medicinal herbs, the potential harm associated with their use should be emphasized. The misconception that herbal preparations are entirely safe is widespread in public, which cannot be the same in the group of medical professionals. Herbal toxicity is not only a result of a lack of quality control over preparing herbs but also due to the wrong belief and lack of knowledge about potential toxicity of herbs (Saad et al., 2006).

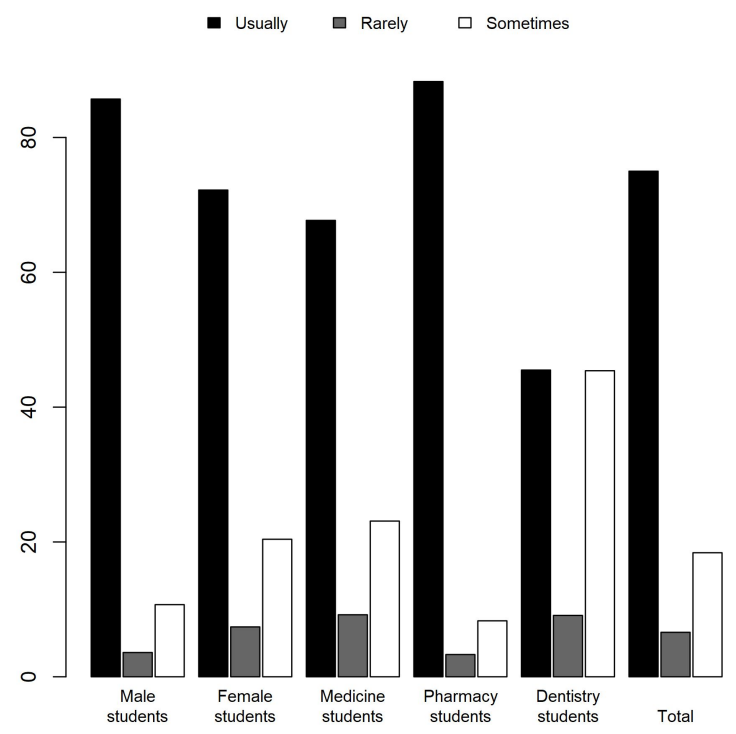

Fig. 6. Frequency (\%) of reading instructions for use, adverse effects and contraindications in relation to the studying groups and sexes

A few studies have shown that prescribers of modern allopathic medicine often have no enough knowledge on herbal medicines and their potential to cause interactions (Clement et al., 2005; Fakeye and Onyemadu, 2008; Xu and Levine, 2008). Possible increase in the number of adverse reactions and health damage caused by these products should be expected in the future, because of the growing number of available herbal products. A study conducted in Belgrade by Samojlik et al. (2013) showed that $73.3 \%$ of the participants, which were patients in pharmacies, consider that the use of herbal preparations is entirely safe, while only $17.4 \%$ believe that the application is not entirely safe. Study of Strgar et al. (2013) conducted in Slovenia showed that $82 \%$ of medical school stu- dents believe that the use of herbal preparations is not entirely safe, compared to $61.9 \%$ of students in the high school. This result also emphasizes the importance of education. A study conducted in India showed that $85.5 \%$ of surveyed students take herbal remedies because they consider them natural, with no side effects.

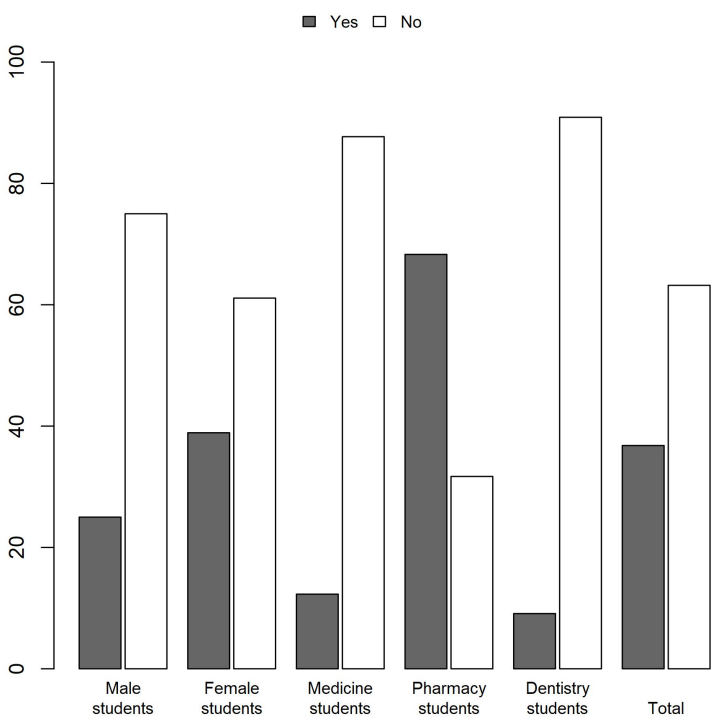

Fig. 7. Frequencies of answers (\%) on question: "Are you satisfied with gained knowledge of herbal preparations during your studies?"

It is worth reporting that students from different studying groups have a different attitude about the acquisition of the necessary knowledge on herbal preparations. Expectedly, pharmacy students are generally convinced that they have the necessary knowledge on herbal preparations (68.3\%). There is $12.3 \%$ of medical students with the same attitude, and only $9.1 \%$ of dentistry students (Figure 7). Using the chi-square test of independence, a statistically significant difference between study groups was proven $\left(\chi^{2}{ }_{(2)}=46.07, p=0.00\right)>\left(\chi_{(2)}^{2}=5.99\right.$, $\mathrm{p}=0.05)$.

There is a small number of medicine and dentistry students satisfied with the gained knowledge of herbal preparations during their studies. These results are positive because students are aware that they do not have enough knowledge. The role of health care professionals, including physicians, in raising public awareness of the proper use of herbs is crucial (Bauer, 2000). Results of the study from Jordan show that seventy percent of students received no adequate advice about herbal preparation use from their physicians. It shows the necessity to educate physicians about this vital topic (Sma et al., 2016). Increasing the level of knowledge of future physicians is necessary. This goal can be achieved by organizing continuous medicine education or incorporating relevant topics in the studying programs.

\section{CONCLUSION}

Obtained results indicated that students of Faculty of Medicine in Niš use herbal preparations, but they are not completely aware of the safety and effects of this therapy method. Considered that physicians are professionals who recommend herbal preparations, the awareness level about the importance of adverse effects and the interaction of herbs and drugs should be raised in this population. This goal can be achieved by introducing phytotherapy material into the curriculum of medicine 
and dentistry studies. It is essential to prepare students for providing optimal care and counseling for their future patients.

\section{ACKNOWLEDGMENTS}

This research was financially supported by the Ministry of Education, Science and Technological Development of the Republic of Serbia (Grant No. III 46013 and III 41018). The authors are also grateful for the support of the Internal Project of Faculty of Medicine, University of Niš, Serbia No. 25, named "Chemical characterization, biological activity and nutritional value of Ribes nigrum L., Salvia sclarea L. and Foeniculum vulgare Miller".

\section{REFERENCES}

Ameade, E. P. K., Amalba, A., Helegbe, G. K. and Mohammed, B. S. (2016). Medical students' knowledge and attitude towards complementary and alternative medicine - A survey in Ghana, Journal of Traditional and Complementary Medicine 6(3): 230-236.

Bauer, B. A. (2000). Herbal therapy: what a clinician needs to know to counsel patients effectively, Mayo Clinic Proceedings 75(8): 835-841.

Bent, S. (2008). Herbal medicine in the United States: Review of efficacy, safety, and regulation: grand rounds at University of California, San Francisco Medical Center, Journal of General Internal Medicine 23(6): 854-859.

Boparai, J., Singh, A., Gupta, A., Matreja, P., Khanna, P., Gupta, V. and Gautam, R. (2017). A study to determine the knowledge and level of awareness of medical undergraduates about herbal medicines and herb-drug interactions, International Journal of Basic and Clinical Pharmacology .

Builders, P. (2019). Introductory Chapter: Introduction to Herbal Medicine, in P. F. Builders (ed.), Herbal Medicine, IntechOpen.

Chekole, G. (2017). Ethnobotanical study of medicinal plants used against human ailments in Gubalafto District, Northern Ethiopia, Journal of Ethnobiology and Ethnomedicine 13(1): 55.

Clement, Y. N., Morton-Gittens, J., Basdeo, L., Blades, A., Francis, M.-J., Gomes, N., Janjua, M. and Singh, A. (2007) Perceived efficacy of herbal remedies by users accessing primary healthcare in Trinidad, BMC Complementary and Alternative Medicine 7(1): 4.

Clement, Y. N., Williams, A. F., Khan, K., Bernard, T., Bhola, S., Fortuné, M., Medupe, O., Nagee, K. and Seaforth, C. E. (2005). A gap between acceptance and knowledge of herbal remedies by physicians: The need for educational intervention, BMC Complementary and Alternative Medicine 5(1): 20.

Corrêa da Silva, M. G., Soares, M. C. F. and Muccillo-Baisch, A. L. (2012). Self-medication in university students from the city of Rio Grande, Brazil, BMC Public Health 12(1): 339.

Ćujić, N., Ibrić, S., Bigović, D., Noveski, N. and Šavikin, K (2015). Stability testing of herbal medicines, Lekovite sirovine (35): 53-60

Ekor, M. (2014). The growing use of herbal medicines: issues relating to adverse reactions and challenges in monitoring safety, Frontiers in Pharmacology 4.
Fakeye, T. O. and Onyemadu, O. (2008). Evaluation of knowledge base of hospital pharmacists and physicians on herbal medicines in Southwestern Nigeria, Pharmacy Practice (Internet) 6(2).

Gardiner, P., Graham, R., Legedza, A. T. R., Ahn, A. C., Eisenberg, D. M. and Phillips, R. S. (2007a). Factors associated with herbal therapy use by adults in the United States, $\mathrm{Al}$ ternative Therapies in Health and Medicine 13(2): 22-29.

Gardiner, P., Kemper, K. J., Legedza, A. and Phillips, R. S. (2007b). Factors associated with herb and dietary supplement use by young adults in the United States, BMC Complementary and Alternative Medicine 7(1): 39.

Howell, L., Kochhar, K., Saywell, R., Zollinger, T., Koehler, J., Mandzuk, C., Sutton, B., Sevilla-Martir, J. and Allen, D. (2006). Use of herbal remedies by Hispanic patients: Do they inform their physician?, The Journal of the American Board of Family Medicine 19(6): 566-578

Kennedy, J., Wang, C.-C. and Wu, C.-H. (2008). Patient Disclosure about Herb and Supplement Use among Adults in the US, Evidence-Based Complementary and Alternative Medicine 5(4): 451-456.

Newberry, H., Beerman, K., Duncan, S., McGuire, M. and Hillers, V. (2001). Use of onvitamin, nonmineral dietary supplements among college students, Journal of American College Health 50(3): 123-129.

Nur, N. (2010). Knowledge and behaviours related to herbal remedies: a cross-sectional epidemiological study in adults in Middle Anatolia, Turkey: Use of herbal remedies, Health $\mathcal{E}$ Social Care in the Community 18(4): 389-395.

Pan, S.-Y., Zhou, S.-F., Gao, S.-H., Yu, Z.-L., Zhang, S.-F., Tang, M.-K., Sun, J.-N., Ma, D.-L., Han, Y.-F., Fong, W.-F. and Ko, K.-M. (2013). New perspectives on how to discover drugs from herbal medicines: CAM's outstanding contribution to modern therapeutics, Evidence-Based Complementary and Alternative Medicine 2013: 1-25.

Perkin, J. E., Wilson, W. J., Schuster, K., Rodriguez, J. and AllenChabot, A. (2002). Prevalence of nonvitamin, nonmineral supplement usage among university students, Journal of the American Dietetic Association 102(3): 412-414.

Petrovska, B. B. (2012). Historical review of medicinal plants' usage, Pharmacognosy Reviews 6(11): 1.

Saad, B., Azaizeh, H., Abu-Hijleh, G. and Said, O. (2006). Safety of Traditional Arab Herbal Medicine, Evidence-Based Complementary and Alternative Medicine 3(4): 433-439.

Samojlik, I., Mijatović, V., Gavarić, N., Krstin, S. and Božin, B. (2013). Consumers' attitude towards the use and safety of herbal medicines and herbal dietary supplements in Serbia, International Journal of Clinical Pharmacy 35(5): 835-840.

Sekhri, K., Bhanwra, S. and Nandha, R. (2013). Herbal products: a survey of students' perception and knowledge about their medicinal use, International Journal of Basic $\mathcal{E}$ Clinical Pharmacology 2(1): 71.

Sma, A., B, A. and Da, D. (2016). Perceptions and use of medicinal herbs among college students at a Jordanian University in Amman-Jordan: traditions supersedes education, Journal of Traditional Medicine E Clinical Naturopathy 05(03).

Sofowora, A., Ogunbodede, E. and Onayade, A. (2013). The role and place of medicinal plants in the strategies for disease prevention, African Journal of Traditional, Complementary and Alternative Medicines 10(5): 210-229. 
Strgar, J., Pilih, M., Pogacnik, M. and Znidarcic, D. (2013). Knowledge of medicinal plants and their uses among secondary and grammar school students: A case study from Slovenia, Archives of Biological Sciences 65(3): 1123-1129.

Wahner-Roedler, D. L., Vincent, A., Elkin, P. L., Loehrer, L. L., Cha, S. S. and Bauer, B. A. (2006). Physicians' attitudes toward complementary and alternative medicine and their knowledge of specific therapies: A survey at an academic medical center, Evidence-Based Complementary and Alternative Medicine 3(4): 495-501.

Walker, P. S. and Donovan, J. A. (1999). Herbal remedies: natural caveats, International Journal of Dermatology 38(10): 746748 .

Xu, S. and Levine, M. (2008). Medical residents' and students' attitudes towards herbal medicines: a pilot study, The Canadian Journal of Clinical Pharmacology = Journal Canadien De Pharmacologie Clinique 15(1): e1-4.

Yoshida, N., Numano, M., Nagasaka, Y., Ueda, K., Tsuboi, H., Tanimoto, T. and Kimura, K. (2015). Study on health hazards through medicines purchased on the Internet: a cross-sectional investigation of the quality of anti-obesity medicines containing crude drugs as active ingredients, BMC Complementary and Alternative Medicine 15(1): 430. 